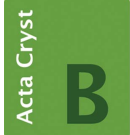

STRUCTURAL SCIENCE CRYSTAL ENGINEERING MATERIALS

ISSN 2052-5206

Keywords: crystal structrure prediction; Cambridge Structural Database.

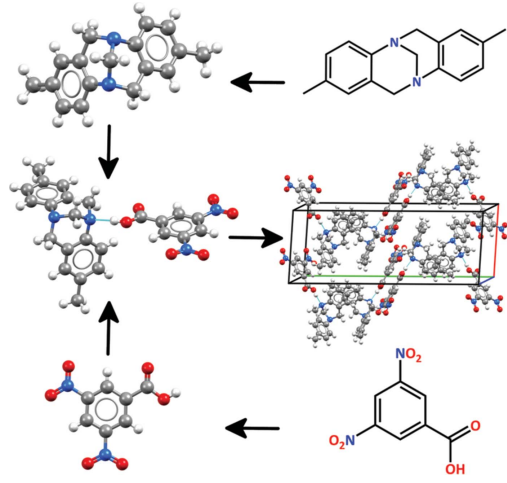

(C) 2016 International Union of Crystallography

\section{Introduction to the special issue on crystal structure prediction}

\author{
Graeme M. Day ${ }^{\mathrm{a} *}$ and Carl Henrik Görbitz ${ }^{\mathrm{b} *}$ \\ ${ }^{a}$ Department of Chemistry, University of Southampton, Highfield Campus, Southampton, Hampshire SO17 1BJ, England, \\ and ${ }^{\mathbf{b}}$ Department of Chemistry, University of Oslo, PO Box 1033 Blindern, N-0315 Oslo, Norway. *Correspondence \\ e-mail: g.m.day@soton.ac.uk, c.h.gorbitz@kjemi.uio.no
}

This special issue was organized to showcase recent work in the area of crystal structure prediction (CSP). The prediction of crystal structures of organic molecules continues to attract considerable interest; the problem is fundamentally attractive for theoreticians and computational scientists, and the methods developed in this area have an important role to play in the development of molecular materials. Acta Crystallographica Section B has had a key role in publishing influential works in this area, in part through publication of the series of blind tests of crystal structure prediction (Lommerse, Motherwell et al., 2000; Motherwell, Ammon et al., 2002; Day, Motherwell et al., 2005; Day, Cooper et al., 2009; Bardwell et al., 2011). These blind tests have been held regularly every 2-3 years since the first 'collaborative workshop held at the Cambridge Crystallographic Data Centre (CCDC) in May 1999' (Lommerse, Motherwell et al., 2000). The role of these exercises, and their accompanying publications, is to provide snapshots of the state of this research field, and this special issue was organized around the publication reporting the results of the sixth blind test (Reilly et al., 2016).

The field has clearly evolved over the years, not least in the number of contributing research groups: the author list of 92 contributors to the sixth blind test paper now spills over a page, compared to the original blind test, which involved 14 of the CSP pioneers. This expansion of the author list reflects an increased range of computational methods that are being applied to the challenge of CSP as well as its varied applications, and it is now, more than ever, impossible to capture the development of this research field in a single report of the blind test results. Anyone with a serious interest in following the research area should read the report on the sixth blind test, but cannot rely on this paper alone as a summary of such an active area. We expect that the set of contributions to the current special issue will help provide a broad view of current CSP research for those who have followed the field, and a valuable entry point to the literature for readers who are new to the area.

The main approach to CSP has remained largely unchanged since the earliest published attempts at ab initio structure prediction (Dzyabchenko, 1984; Gavezzotti, 1991; Gdanitz, 1992; Holden, Du et al., 1993; van Eijck, Mooij et al., 1995; Williams, 1996): trial crystal structures are created and assessed based on their calculated energies. The perfect theoretical approach to lattice energy calculations still does not exist and we should not expect the field to converge to a single method; users of CSP methods benefit greatly from having a range of available, validated options for their calculations, to make choices depending on the type of molecule being studied and available computational resources. Therefore, the development and careful assessment of approaches for calculating accurate lattice energies continue to feature heavily in CSP-related publications. A number of contributions to this special issue describe research in this area, including the development of atom-atom force fields aimed at pharmaceutical applications (Broo \& Nilsson Lill, 2016) and advanced, atomic multipole-based models (Pyzer-Knapp et al., 2016; Elking et al., 2016). The methods used in the current blind test show a clear trend towards an increased use of solid-state electronic structure methods for evaluating lattice energies. Brandenburg \& Grimme (2016) present an evaluation of various quantum chemical methods on the target molecules in the sixth blind test, using both density functional theory (DFT) and semi-empirical methods, and suggest a set of these structures as a benchmark for testing such methods. Another developing trend in CSP is towards the evaluation of free energies in place of lattice energies, to allow thermal and 
pressure effects on the structural landscape to be evaluated; Heit \& Beran's (2016) contribution addresses the question of whether including thermal expansion in the models is important for the energetic evaluation of structures.

Another important ingredient in CSP is the method used to generate trial structures and explore the space of crystal structures available to a given molecule. Cole et al. (2016) investigate the use of known crystal structures from the Cambridge Structural Database as templates for predicting crystal structures of similarly shaped molecules. Schneider et al. (2016) describe an enhanced molecular dynamics approach for exploring the free energy surface for crystalline benzene and naphthalene, demonstrating that the method is promising for predicting structures, as well as packing defects.

Finally, two contributions describe the application of CSP. Mohamed et al. (2016) apply CSP to two pharmaceutical salts, as an evaluation of the predictive ability of current methods, and to examine whether the resulting landscape of structures helps explain their hydration behaviour. Curtis et al. (2016), as well as evaluating the performance of various DFT methods on one of the blind test targets, examine how electronic properties such as the band gap vary between predicted structures, demonstrating how the results of CSP could be used to screen organic molecular semiconductors.

The special issue demonstrates the breadth of research in the area of CSP and we hope that the issue will stimulate interest and new research in this area, as well as the publication of future research in Acta Crystallographica Section B. We thank all of the authors who have contributed to this varied and high quality issue.

\section{References}

Bardwell, D. A., Adjiman, C. S., Arnautova, Y. A., Bartashevich, E., Boerrigter, S. X. M., Braun, D. E., Cruz-Cabeza, A. J., Day, G. M., Della Valle, R. G., Desiraju, G. R., van Eijck, B. P., Facelli, J. C., Ferraro, M. B., Grillo, D., Habgood, M., Hofmann, D. W. M., Hofmann, F., Jose, K. V. J., Karamertzanis, P. G., Kazantsev, A. V., Kendrick, J., Kuleshova, L. N., Leusen, F. J. J., Maleev, A. V., Misquitta, A. J., Mohamed, S., Needs, R. J., Neumann, M. A., Nikylov, D., Orendt, A. M., Pal, R., Pantelides, C. C., Pickard, C. J., Price, L. S., Price, S. L., Scheraga, H. A., van de Streek, J., Thakur, T. S., Tiwari, S., Venuti, E. \& Zhitkov, I. K. (2011). Acta Cryst. B67, $535-551$.

Brandenburg, J. G. \& Grimme, S. (2016). Acta Cryst. B72, 502-513. Broo, A. \& Nilsson Lill, S. O. (2016). Acta Cryst. B72, 460-476.

Cole, J. C., Groom, C. R., Read, M. G., Giangreco, I., McCabe, P., Reilly, A. M. \& Shields, G. P. (2016). Acta Cryst. B72, 530-541. Curtis, F., Wang, X. \& Maro, N. (2016). Acta Cryst. B72, 562-570.

Day, G. M., Cooper, T. G., Cruz-Cabeza, A. J., Hejczyk, K. E., Ammon, H. L., Boerrigter, S. X. M., Tan, J. S., Della Valle, R. G., Venuti, E., Jose, J., Gadre, S. R., Desiraju, G. R., Thakur, T. S., van Eijck, B. P., Facelli, J. C., Bazterra, V. E., Ferraro, M. B., Hofmann,
D. W. M., Neumann, M. A., Leusen, F. J. J., Kendrick, J., Price, S. L., Misquitta, A. J., Karamertzanis, P. G., Welch, G. W. A., Scheraga, H. A., Arnautova, Y. A., Schmidt, M. U., van de Streek, J., Wolf, A. K. \& Schweizer, B. (2009). Acta Cryst. B65, 107-125.

Day, G. M., Motherwell, W. D. S., Ammon, H. L., Boerrigter, S. X. M., Della Valle, R. G., Venuti, E., Dzyabchenko, A., Dunitz, J. D., Schweizer, B., van Eijck, B. P., Erk, P., Facelli, J. C., Bazterra, V. E., Ferraro, M. B., Hofmann, D. W. M., Leusen, F. J. J., Liang, C., Pantelides, C. C., Karamertzanis, P. G., Price, S. L., Lewis, T. C., Nowell, H., Torrisi, A., Scheraga, H. A., Arnautova, Y. A., Schmidt, M. U. \& Verwer, P. (2005). Acta Cryst. B61, 511-527.

Dzyabchenko, A. V. (1984). J. Struct. Chem. 25, 416-420.

Eijck, B. P. van, Mooij, W. T. M. \& Kroon, J. (1995). Acta Cryst. B51, 99-103.

Elking, D. M., Fusti-Molnar, L. \& Nichols, A. (2016). Acta Cryst. B72, 488-501.

Gavezzotti, A. (1991). J. Am. Chem. Soc. 113, 4622-4629.

Gdanitz, R. J. (1992). Chem. Phys. Lett. 190, 391-396.

Heit, Y. N. \& Beran, G. J. O. (2016). Acta Cryst. B72, 514-529.

Holden, J. R., Du, Z. Y. \& Ammon, H. L. (1993). J. Comput. Chem. 14, 422-437.

Lommerse, J. P. M., Motherwell, W. D. S., Ammon, H. L., Dunitz, J. D., Gavezzotti, A., Hofmann, D. W. M., Leusen, F. J. J., Mooij, W. T. M., Price, S. L., Schweizer, B., Schmidt, M. U., van Eijck, B. P., Verwer, P. \& Williams, D. E. (2000). Acta Cryst. B56, 697-714.

Mohamed, S., Karothu, D. P. \& Naumov, P. (2016). Acta Cryst. B72, 551-561.

Motherwell, W. D. S., Ammon, H. L., Dunitz, J. D., Dzyabchenko, A., Erk, P., Gavezzotti, A., Hofmann, D. W. M., Leusen, F. J. J., Lommerse, J. P. M., Mooij, W. T. M., Price, S. L., Scheraga, H., Schweizer, B., Schmidt, M. U., van Eijck, B. P., Verwer, P. \& Williams, D. E. (2002). Acta Cryst. B58, 647-661.

Pyzer-Knapp, E. O., Thompson, H. P. G. \& Day, G. M. (2016). Acta Cryst. B72, 477-487.

Reilly, A. M., Cooper, R. I., Adjiman, C. S., Bhattacharya, S., Boese, A. D., Brandenburg, J. G., Bygrave, P. J., Bylsma, R., Campbell, J. E., Car, R., Case, D. H., Chadha, R., Cole, J. C., Cosburn, K., Cuppen, H. M., Curtis, F., Day, G. M., DiStasio Jr, R. A., Dzyabchenko, A., van Eijck, B. P., Elking, D. M., van den Ende, J. A., Facelli, J. C., Ferraro, M. B., Fusti-Molnar, L., Gatsiou, C.-A., Gee, T. S., de Gelder, R., Ghiringhelli, L. M., Goto, H., Grimme, S., Guo, R., Hofmann, D. W. M., Hoja, J., Hylton, R. K., Iuzzolino, L., Jankiewicz, W., de Jong, D. T., Kendrick, J., de Klerk, N. J. J., Ko, H.Y., Kuleshova, L. N., Li, X., Lohani, S., Leusen, F. J. J., Lund, A. M., Lv, J., Ma, Y., Marom, N., Masunov, A. E., McCabe, P., McMahon, D. P., Meekes, H., Metz, M. P., Misquitta, A. J., Mohamed, S., Monserrat, B., Needs, R. J., Neumann, M. A., Nyman, J., Obata, S., Oberhofer, H., Oganov, A. R., Orendt, A. M., Pagola, G. I., Pantelides, C. C., Pickard, C. J., Podeszwa, R. 1., Price, L. S., Price, S. L., Pulido, A., Read, M. G., Reuter, K., Schneider, E., Schober, C., Shields, G. P., Singh, P., Sugden, I. J., Szalewicz, K., Taylor, C. R., Tkatchenko, A., Tuckerman, M. E., Vacarro, F., Vasileiadis, M., Vázquez-Mayagoitia, Á., Vogt, L., Wang, Y., Watson, R. E., de Wijs, G. A., Yang, J., Zhu, Q. \& Groom, C. R. (2016). Acta Cryst. B72, 439-459.

Schneider, E., Vogt, L. \& Tuckerman, M. E. (2016). Acta Cryst. B72, $542-550$.

Williams, D. E. (1996). Acta Cryst. A52, 326-328. 